\title{
Towards Third Generation Universities in Iran: Wish or Necessity
}

\author{
Seyed Behnamedin Jameie ${ }^{1,2, *}$ \\ ${ }^{1}$ Neuroscience Research Center, Iran University of Medical Sciences Tehran, Iran \\ ${ }^{2}$ Department of Medical Basic Sciences, Iran University of Medical Sciences, Tehran, Iran \\ "Corresponding author: Professor of Anatomy and Neuroscience, Neuroscience Research center, Iran University of Medical Sciences, Tehran, Iran. Email: jameie.sb@iums.ac.ir
}

Received 2018 October 14; Accepted 2018 October 14

Keywords: Third Generation Universities, Research and Education Based Universities

Universities are committed to upgrading human knowledge. Countries have different dates of establishing universities. There are old well-known universities, and new generation of universities are in the process of being established. Universities are changing in fundamental ways, moving from the traditional model of science and education to universities with vision of society leadership, creating wealth and innovation. Education- and researchbased universities are considered as the first and second generation universities (1\&2GUs). Along with the rapid growth of technology and changes in communities and human needs, universities have also changed. Universities in developed countries have gradually crossed boundaries of $1 \& 2 \mathrm{GUS}$ and entered a new era. Universities in these countries, while embracing their mission, have entered a new generation of academic activities, by preserving their previous functions. The formation of third generation universities (3GUs) is dependent on developed structures and infrastructures of these societies, as well as their valuable achievements in $1 \& 2$ GUs. Iran has a long history of higher education. Jundishapur Academy is known as one of the oldest universities around the world. Before the Islamic Revolution, credible universities in Iran, such as the University of Tehran, Shiraz University and Polytechnic University, have been involved in academic activity at the national and international levels and considered as $1 \& 2$ GUs. Since the 1970 s, the number of universities and institutes of higher education has grown explosively, so that in a short time, the total number of Iranian Universities (IRUs) exceeded the total number of universities in developed European countries. The process of establishing new universities has continued until recently. Significant differences in the ranking of IRUs influence the future trend of these universities for entering next generations.

Medieval or first generation universities (1GUs) mainly focused on education and did not engage in what is now called research. They were devoted to teaching, aiming at creating good theologians, engineers, lawyers, and physicians. Their vision is to upgrade training standards and increase the number of skilled graduates in different disciplines. 1GUs act more locally, professionalism is their main output; the managing role of the university chancellor is dominant, and the production and protection of scientific findings accepted as their main role (Wissema 2009). Given the vast achievements of research, all universities in developed and most universities in developing countries have gone through this phase. There are good examples of 1GUs in ancient Iran and Iran before and after the Islamic Revolution (1). During the 6th and 7th centuries, the Academy of Gondishapur (AG) was the most important educational medical center of the ancient world, and acted nationally and regionally, and had research programs. Furthermore, AG was at that time ahead of $1 \mathrm{GU}$ and could be considered as a second generation university (2GU). There were no similar educational centers like AG at that time in other powerful existing nations, such as the Roman Empire. Accordingly, Iran was a pioneer in transition to second generation universities (2GUs) in the ancient world. Unfortunately, Iran's superiority over science and technology did not last for a long time, with the invasion of Iran by hostile nations during different periods of its history and the establishment of unworthy governments, the "sun of knowledge and education" collapsed for many years. Only during the last century of the second millennium, Iran, which in many fields is considered as a backward country, gradually began to enter a new era of education. At that time, enemy governments occupied the country and there was no powerful central government and Iran encountered many economic, political, health and education problems that darkened the vision of improvement. These conditions did not allow any enhancement in education. With the exception of the Darul-Fonoun Institute, founded 
in 1851 by Mirza Taghi Khan Amir Kabir, as the first symbol of higher education institution in modern Iran, there is no other evidence of higher education until the early twenty century. It is important to mention that the word "Darul-Fonoun", which is the equivalent of "Polytechnics", has been used for many years in the title of the European higher education institutions. Nonetheless, in 1934, the first IRU, Tehran University, established the first step for entering in the world of scientific competitions. Since then, the development of new IRUs has expanded rapidly, including Shiraz (1946), Isfahan (1948), Amir Kabir (1958), Shahid Beheshti (1959), and Sharif Universities (1966). The established universities continued in a manner appropriate to population and general conditions of the country until the Islamic Revolution in 1978. After the revolution, the number of IRUs, independent of higher education schools, and the branches of the Islamic Azad University explosively increased. In addition, medical and non-medical schools and universities separated and two different ministries supervised them. The new condition dramatically influenced higher education in Iran. Both pre- and post-revolutionary universities have been ranked as successful 1GUs. However, there are significant downsides and weaknesses in the evaluation of their educational function. Since the success of entering next generation of universities depends on the performance of 1GUs, the discussion on current educational problems at IRUs are a necessity and if these educational issues are not solved, the transition to the new generation seems impossible. In either case, IRUs have been through 1GUs and entered the 2GUS. When and how IRUs entered the 2GUS is not clear. During the last two decades, the mission of IRUs changed and more attention has been paid to the priority of research. Many research centers have been developed, equipped with expensive and modern facilities, and many postgraduate students are accepted by universities. All of these are considered as the beginning of a new entry to 2GUs. Whether all these universities had any research strategic plans is not clear to the authors. During a short time, the total number of research centers of all governmental or non-governmental IRUs increased more than all European countries' research centers. With this, it was expected for Iranian scholars to achieve the peaks of research. In fact, IRUs and researchers came to $2 \mathrm{GUS}$ and Iran was ranked first in the number of scientific articles among Middle Eastern countries (2). If not all IRUs, at least most of them claim that they came to 2GUs, successfully. Furthermore, 2GUs are research-based universities and their education is in line with research. The students learn how to think about a research project, how to engage in it and how to interpret the results. Research and education of research is the dominant function of $2 \mathrm{GUs}$. $2 \mathrm{GUs}$ act more nationally, answer to the society's demands and the formal language of these universities is the national language. The management of 2 GUs is headed by a team consisting of university chancellors and professors.

Until upgrading to 2GUs, medical and non-medical IRUs seem to be on the almost same conditions. Due to the author's commitment to medical disciplines, the remaining part of the paper mainly focused on medical universities in the matter of 3GUs. The vision and mission of medical universities are somewhat different from non-medical disciplines. In addition to education and research, medical universities have an important role in the community health system and strategic policy making in this regard. Therefore, this key role should be taken in account for any transition in the mission of these institutions to 3GUs.

Several questions have been raised with tendency towards 3GUs. How many universities in the world are third generation universities? Is there any general global pattern for transition to 3GUs? What are the factors and conditions of transferring 2GUs to 3GUs? Certainly, some universities in advanced countries entered 3GUs and even 4GUs. The essentiality in 3GUs is to present the information produced by providing university-industry cooperation for use as a patent or technology to industry/market $(1,3)$. In other words, 3GUs offer an effective providing universityindustry cooperation in the world. In addition, 3GUs universities play a new role as incubators of new science- or technology-based commercial activities and take an active role in the exploitation of knowledge they create. To reach 3GUs in addition to the attitudes and approaches of relevant authorities of the country and universities to move to 3GUs, well-developed industrial, economic, and social infrastructures are necessary. Achieving the goals of $1 \mathrm{Gus}$ and 2 Gus, economic growth indicators, political stability, independency of universities in their decision and policy making, having a clear strategic plan, established and launched science and technology incubators, and knowledge and willingness of faculty members are important factors for crossing of the 2GUs (4). Looking at the current conditions of medical IRUs and considering formal governmental statistics on the above factors, in the most optimistic situation, the number of medical universities in the country that have conditions entering 3GUs is very limited. Moving towards 3GUs is inevitable and seems to be a global necessity for promotion of responsive science to society demands and problems. In conclusion, it is very necessary to do an intensive critical study on the current situation and the success rate of IRUs in achieving their previous goals. After that and only in case of availability of the surrounding conditions and factors, with predictable and measurable planning, moving towards 3GUs could become possible. 


\section{Footnotes}

Conflict of Interests: None declared.

Funding/Support: None declared.

\section{References}

1. Wissema JG. Towards the third generation university; managing the university in transition. 1st ed. Edward Elgar Publishing Limited; 2009. doi: $10.4337 / 9781848446182$.
2. Ramezan Ghorbani N, Fakour Y, Nojoumi SA. The increasing trend in global ranking of websites of Iranian Medical Universities during January 2012-2015. Iran J Public Health. 2017;46(8):1095-103. [PubMed: 28894711]. [PubMed Central: PMC5575389].

3. Lukovics M, Zuti B. New functions of universities in century XXI towards "fourth generation" universities. Transition Stud Rev. 2015;22(2):33-48.

4. Skribans V, Lektauers A, Merkuryev Y. Third generation university strategic planning model development. Proceedings of the 31th International Conference of the System Dynamics Society. Munich Personal RePEc Archive; 2013. p. 1-7. 